\title{
New Kinetic Spectrophotometric Method for Determination of Folic Acid in Pharmaceutical Formulations
}

\author{
Mouhammed Khateeb ${ }^{1 *}$, Basheer Elias ${ }^{2}$, Fatema AL Rahal ${ }^{2}$ \\ ${ }^{1}$ Department of Basic sciences, Faculty of Mechanical and Electrical Engineering, University of Al- \\ Baath, Homs, Syria \\ ${ }^{2}$ Department of Chemistry, Faculty of Sciences, University of Al- Baath Homs, Syria \\ *E-mail: drkhateeb2010@gmail.com, mkhateeb74@hotmail.com
}

Keywords: Folic acid; kinetic spectrophotometry; potassium ferricyanide; pharmaceutical formulations

\begin{abstract}
A simple and sensitive kinetic spectrophotometric method has been developed for the determination of folic acid (FA) in bulk and pharmaceutical Formulations. The method is based on the oxidation of FA by Fe(III) in sulfuric acid medium. Fe(III) subsequently reduces to Fe(II) which is coupled with potassium ferricyanide to form Prussian blue. The reaction is followed spectrophotometrically by measuring the increase in absorbance at $\lambda \max 725 \mathrm{~nm}$. The rate data and fixed time methods were adopted for constructing the calibration curves. The linearity range was found to be $1-20 \mu \mathrm{g} \mathrm{mL}^{-1}$ for each method. The correlation coefficient was 0.9978 and 0.9993 , and LOD was found to be 0.91 and $0.09 \mu \mathrm{g} \mathrm{mL}^{-1}$ for rate data and fixed time methods, respectively. The proposed method has been successfully applied to the determination of FA in formulations with no interference from the excipients. Statical comparison of the results shows that there is no significant difference between the proposed and pharmacopoeial methods.
\end{abstract}

\section{INTRODUCTION}

Folic acid (FA) or vitamin B9, chemically known as N-[4-[[(2-amino-1,4-dihydro-4-oxo-6pteridinyl)methyl]amino]benzoyl]-L-glutamic acid (Figure 1). FA was one of the water-soluble vitamin B groups that is a tasteless and odorless yellowish orange crystal [1]. FA has been identified as one of the most important vitamin for normal human metabolic function. The amount of FA perception is proper to neural tube defects in newborns, cardiovascular diseases, colon cancer and certain anemia. Also, FA is essential for cell growth and division substances. It promotes the synthesis of protein from amino acid [2].

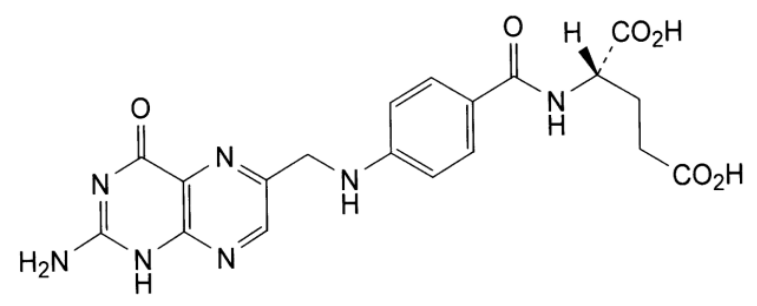

Figure 1.Chemical structure of folic acid.

Different methods have been developed for the determination of FA in pharmaceutical formulation including colorimetric [3], spectrophotometry [4], chemiluminescence [5-6], flow injection analysis [7-8], spectrofluorimetric [9], capillary electrophoresis [10], voltammetry [1112]. More specific high-performance liquid chromatographic (HPLC) methods have been developed with UV detection to identify different forms of FA [13-15]. Recently, highly specific HPLC-Mass spectrometric (HPLC-MS) methods have been reported for the analysis of FA in pharmaceutical 
formulations [16]. FA was determined with kinetic spectrophotometric method based on the inhibitory effect of folic acid on the reaction of thionine and bromate in sulfuric acid media [17].

Kinetic spectrophotometric methods were a powerful analytical technique that has excellent sensitivity, sufficient accuracy and requires relatively simple and inexpensive instrumentation. These advantages make it as an attractive method for the determination of different species in various samples at trace levels $[18,19]$.

To our best knowledge, no attempts have been made to determine FA with Fe(III) and potassium ferricyanide by any kinetic spectrophotometric method and the literatures are still poor in such analytical procedures. So, in this paper, a kinetic spectrophotometric method for the determination of FA is described. The method is based on the oxidation of FA by Fe(III) in sulfuric acid medium; Fe(III) subsequently reduced to $\mathrm{Fe}(\mathrm{II})$, which reacts with potassium ferricyanide to form a Prussian blue product, absorbing maximally at $725 \mathrm{~nm}$. Optimum conditions were established and the method was validated for linearity, sensitivity, accuracy and precision.

\section{EXPERIMENTAL}

\subsection{Apparatus}

A Jasco V-530 UV-VIS spectrophotometer (Japan) with $1 \mathrm{~cm}$ quartz cells was used for all absorbance measurements under the following operating conditions: scan speed medium (400 $\mathrm{nm} / \mathrm{min}$ ), scan range $200-1100 \mathrm{~nm}$ and slit width $2 \mathrm{~nm}$. Spectra were automatically obtained by Jasco system software. $\mathrm{pH}$ measurements were made with ORION 250A (USA) with combined glass $\mathrm{pH}$ electrode.

\subsection{Reagents and materials}

All chemicals and reagents were of analytical or pharmaceutical grade and solutions were prepared with doubly distilled water. Folic acid was obtained from Qualikems (India). The purity of FA was $98.0 \%$ according to BP [1]. Pharmaceutical preparations containing FA were purchased from commercial sources in the local market. Ammonium ferric sulfate and potassium ferricyanide were obtained from (Fluka Chemie AG, Switzerland). Stock standard solution of FA $\left(100 \mu \mathrm{g} \mathrm{mL}^{-1}\right)$ was prepared by dissolving $10.2 \mathrm{mg}$ of FA in $0.2 \mathrm{~mL}$ of $2.0 \mathrm{M} \mathrm{NaOH}$ solution and diluting to 100 $\mathrm{mL}$ with bi-distilled water. $3.0 \times 10^{-3} \mathrm{M}$ of Ammonium ferric sulfate solution was prepared by dissolving the accurately weighed amount of the pure solid in $3.0 \times 10^{-3} \mathrm{M} \mathrm{H}_{2} \mathrm{SO}_{4} .2 .5 \times 10^{-3} \mathrm{M}$ of potassium ferricyanide was prepared by dissolving the accurately weighed amount of the pure solid in doubly distilled water. All solutions were stored at $4{ }^{\circ} \mathrm{C}$, and protected from the light in dark bottles and kept in the refrigerator for not more than 5 days.

\subsection{Procedure for rate data method}

Aliquots of 1-20 $\mu \mathrm{g} \mathrm{mL}^{-1}$ of FA stock solution $\left(0.1-2.0 \mathrm{~mL}, 100 \mu \mathrm{g} \mathrm{mL}{ }^{-1}\right)$, were pipetted into a series of $10 \mathrm{~mL}$ volumetric flask. $2.5 \mathrm{~mL}$ of ammonium ferric sulfate solution $\left(3.0 \times 10^{-3} \mathrm{M}\right)$, was added followed by $1.5 \mathrm{~mL}$ of potassium ferricyanide solution $\left(2.5 \times 10^{-3} \mathrm{M}\right)$ to each flask and then diluted to the volume with double distilled water at $25{ }^{\circ} \mathrm{C}$. The content of mixture of each flask was mixed well and the increase in absorbance at $725 \mathrm{~nm}$ was recorded as a function of time over 5-20 min against reagent blank treated similarly. The rate data of the reaction $(v)$ at different concentrations was obtained from the slope of the tangent to absorbance time curves. The calibration graphs were constructed by plotting the logarithm of the rate data of the reaction $(\log v)$ versus logarithm of molar concentration of FA $(\log C)$.

\subsection{Procedure for fixed time method}

Aliquots of $1-20 \mu \mathrm{g} \mathrm{mL}^{-1}$ of FA stock solution $\left(0.1-2.0 \mathrm{~mL}, 100 \mu \mathrm{g} \mathrm{mL} \mathrm{m}^{-1}\right)$, were pipetted into a series of $10 \mathrm{~mL}$ volumetric flask. $2.5 \mathrm{~mL}$ of ammonium ferric sulfate solution $\left(3.0 \times 10^{-3} \mathrm{M}\right)$, was added followed by $1.5 \mathrm{~mL}$ of ferricyanide solution $\left(2.5 \times 10^{-3} \mathrm{M}\right)$ to each flask and then diluted to the volume with double distilled water at $25{ }^{\circ} \mathrm{C}$. The content of mixture of each flask, was mixed well 
and the absorbance of each sample solution at preselected fixed time (15 min) was accurately measured and plotted against the final concentration of the FA.

\subsection{Procedure for pharmaceutical formulations}

Twenty tablets were powdered and mixed thoroughly. An amount corresponding to $10 \mathrm{mg}$ of FA was weighed, dissolved with $0.2 \mathrm{~mL}$ of $2.0 \mathrm{M} \mathrm{NaOH}$ solution and diluting to $100 \mathrm{~mL}$ with double distilled water. The volumetric flask was sonicated for $30 \mathrm{~min}$. The solution was filtered through a Whatman filter paper (No. 1) and the resulting solution was used for analysis by the recommended procedures in the concentration range mentioned above.

\section{RESULTS AND DISCUSSION}

$\mathrm{Fe}(\mathrm{III})$ in sulfuric acid medium oxidizes FA and $\mathrm{Fe}(\mathrm{III})$ subsequently reduces to $\mathrm{Fe}(\mathrm{II})$ which is coupled with potassium ferricyanide to form Prussian blue.

$$
\begin{aligned}
& \text { Folic Acid }_{(\text {Reductant }))}+\mathrm{Fe}^{3+} \rightarrow \text { Folic Acid }_{(\text {Oxidant }))}+\mathrm{Fe}^{2+} \\
& \mathrm{Fe}^{2+}+\left[\mathrm{Fe}(\mathrm{CN})_{6}\right]^{3-}+\mathrm{K}^{+}+\mathrm{H}_{2} \mathrm{O} \leftrightarrows \mathrm{FeK}\left[\mathrm{Fe}(\mathrm{CN})_{6}\right] \cdot \mathrm{H}_{2} \mathrm{O}
\end{aligned}
$$

Prussian blue absorbs maximally at $725 \mathrm{~nm}$ as shown in Figure 2. The increase in the intensity of the color by time was used as a basis for a useful kinetic method for the determination of FA in pharmaceutical formulations.

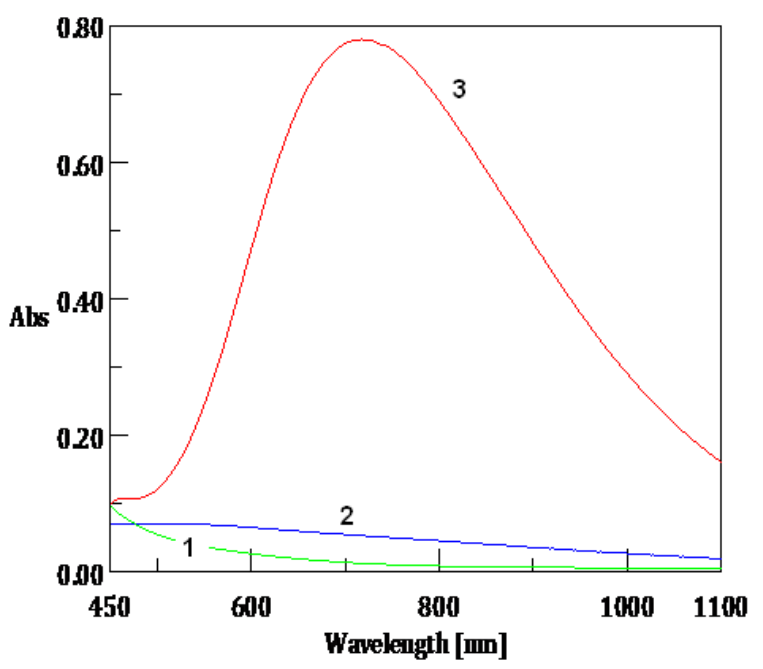

Figure 2. Absorption spectra of (1) $15 \mu \mathrm{g} \mathrm{mL}^{-1} \mathrm{FA}$ against water, (2) reagent blank solution against water and (3) the reaction product of $\mathrm{C}_{\mathrm{FA}}=15 \mu \mathrm{g} \mathrm{mL} \mathrm{mL}^{-1}+2.5 \mathrm{~mL} \mathrm{Fe}(\mathrm{III})\left(3.0 \times 10^{-3} \mathrm{M}\right)+1.5 \mathrm{~mL}$ $\mathrm{K}_{3}\left[\mathrm{Fe}(\mathrm{CN})_{6}\right]\left(2.5 \times 10^{-3} \mathrm{M}\right)$ against reagent blank, time $15 \mathrm{~min}$.

\subsection{Optimization of reaction conditions}

The spectrophotometric properties of the colored product as well as the different experimental parameters affecting the color development and its stability were studied and optimized by changing each variable in turn, while keeping all others constants. In all experiments, FA concentration was constant $15 \mu \mathrm{g} \mathrm{mL} \mathrm{m}^{-1}$. The effect of ammonium ferric sulfate solution concentration on the reaction was studied over the range $2.25 \times 10^{-4}-8.25 \times 10^{-4} \mathrm{M}$, in the final concentration. The maximum absorbance was obtained at concentration of $7.5 \times 10^{-4} \mathrm{M}$ (when 2.5 $\mathrm{mL}$ of $3.0 \times 10^{-3} \mathrm{M} \mathrm{Fe}(\mathrm{III})$ was added. Higher concentration of ammonium ferric sulfate $\left(>7.5 \times 10^{-4}\right.$ $\mathrm{M})$ yielded lower absorbance values, probably due to decomposition of the product. The influence of the potassium ferricyanide was investigated between $1.25 \times 10^{-4}$ and $6.25 \times 10^{-4} \mathrm{M} .3 .75 \times 10^{-3} \mathrm{M}$ potassium ferricyanide in the final concentration $\left(1.5 \mathrm{~mL}\right.$ of $2.5 \times 10^{-3} \mathrm{M}$ potassium ferricyanide) was chosen for all subsequent experiments (Figure 3). 


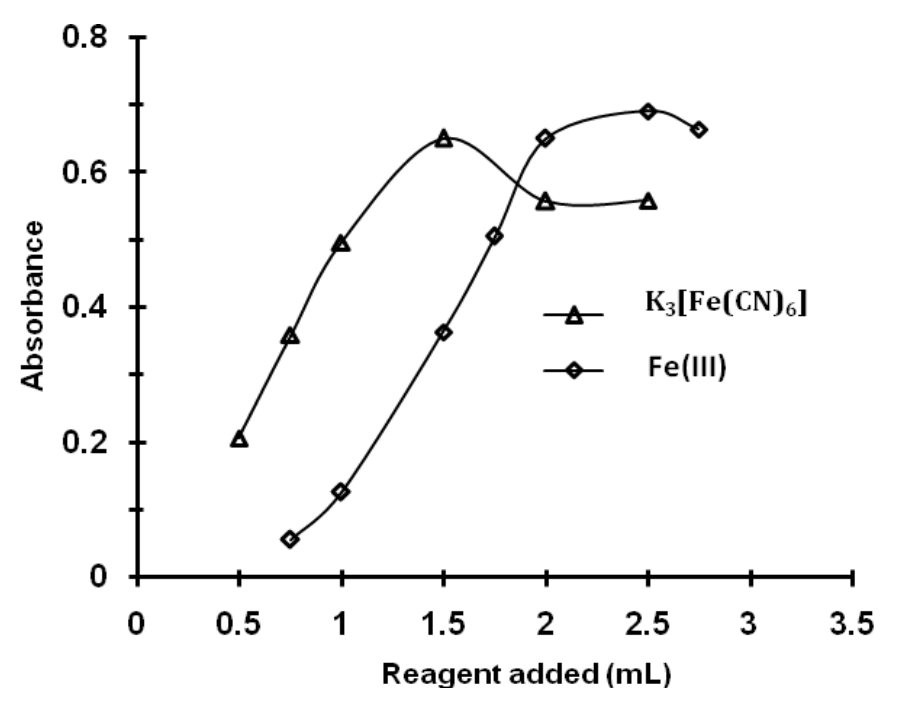

Figure 3. Effect of $3.0 \times 10^{-3} \mathrm{M} \mathrm{Fe}(\mathrm{III})$ and $2.5 \times 10^{-3} \mathrm{M} \mathrm{K}_{3}\left[\mathrm{Fe}(\mathrm{CN})_{6}\right]$ volume on the absorbance at $725 \mathrm{~nm}$ of reaction product of $15 \mu \mathrm{g} \mathrm{mL}^{-1}$ FA measured at room temperature in final volume of 10 $\mathrm{mL}$, time $15 \mathrm{~min}$.

\subsection{Quantitation methods}

Because the intensity of the color increased at $725 \mathrm{~nm}$ with time (Figure 4), this was used as the basis for a useful kinetic method for the determination of FA. The rate data, rate constant, fixed absorbance and fixed time methods [20,21] were carried out and the most suitable analytical methods were chosen regarding the applicability, sensitivity, the values of the intercept and correlation coefficient (r).

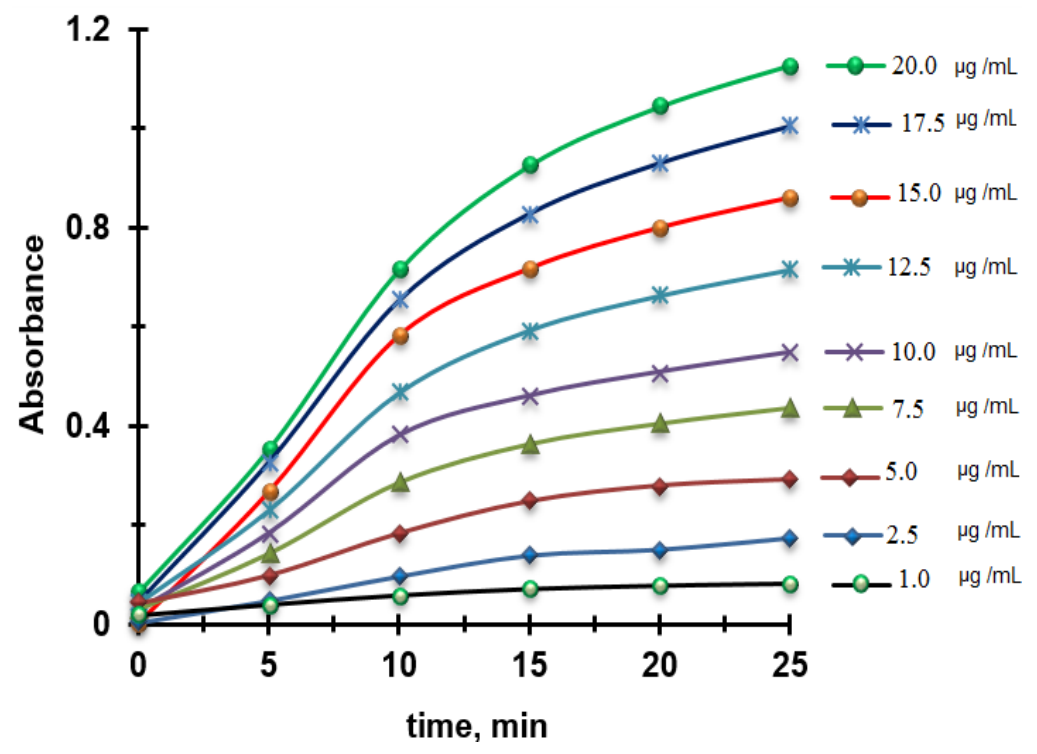

Figure 4. Absorbance-time curve for reaction of $\mathrm{FA}$ with $\mathrm{Fe}(\mathrm{III}) ; \mathrm{C}_{\mathrm{FA}}=1-20 \mu \mathrm{g} \mathrm{mL}^{-1}$.

\subsubsection{Rate data method}

The rate data of reaction would follow a pseudo order rate constant and obeyed the following rate equation:

$$
v=\frac{\Delta \mathrm{A}}{\Delta \mathrm{t}}=\mathrm{k}^{\prime} \cdot C^{\mathrm{n}} .
$$

Where $v$ is the reaction rate, $\mathrm{A}$ is the absorbance, $\Delta A=A_{t_{2}}-A_{t_{1}}, \mathrm{t}$ is the measuring time, $\Delta \mathrm{t}=\mathrm{t}_{2}-\mathrm{t}_{1}$, $\mathrm{k}^{\prime}$ is the pseudo order rate constant, $C$ is the concentration of the vitamin mol $\mathrm{L}^{-1}$ and $\mathrm{n}$ is the order of the reaction. A calibration curve was constructed by plotting the logarithm of the rate of reaction 
$(\log v)$ versus $\operatorname{logarithm}$ of vitamin concentration $(\log C)$, which showed a linear relationship over the concentration range of $1-20 \mu \mathrm{g} \mathrm{mL}^{-1}$ (Figure 5). The logarithmic form of the above equation is written as follows: $\log v=\log \frac{\Delta \mathrm{A}}{\Delta \mathrm{t}}=\log \mathrm{k}^{\prime}+\operatorname{nlog} C$

$$
\operatorname{logv}=\log \frac{\Delta \mathrm{A}}{\Delta \mathrm{t}}=0.9771+0.9439 \log [\mathrm{FA}], \quad(\mathrm{r}=0.9978)
$$

Thus, $\mathrm{k}^{\prime}=9.49 \mathrm{~s}^{-1}$, and the reaction is the first order $(\mathrm{n}=0.9608 \approx 1)$ with respect to FA concentration. $\log \mathrm{C}, \mathrm{M}$

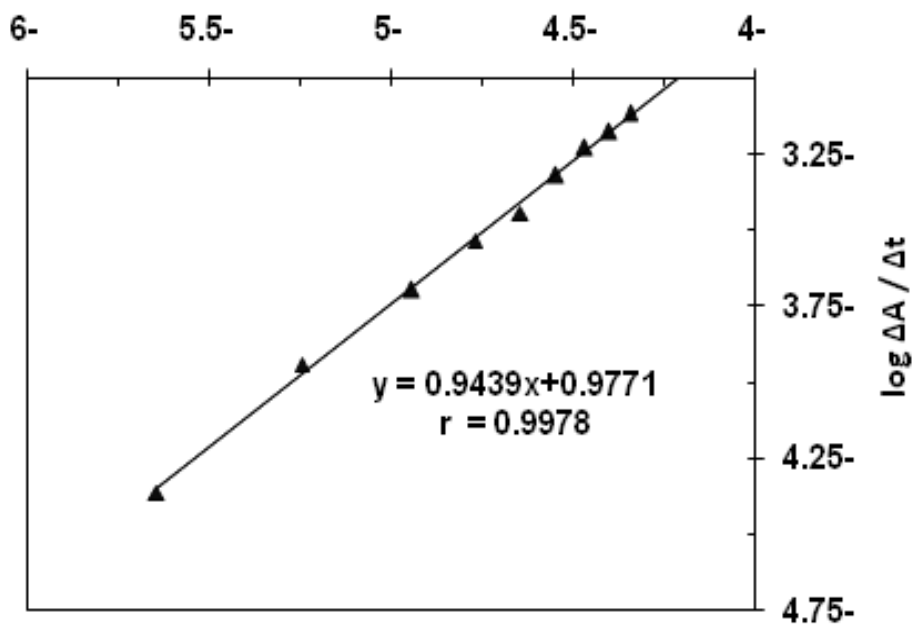

Figure 5. Calibration plot of logarithm rate of the reaction against logarithm molar concentration of FA for rate method, $\left(\mathrm{t}_{1}=5 ; \mathrm{t}_{2}=20 \mathrm{~min}\right)$.

\subsubsection{Rate constant method}

The logarithm of the absorbance of reaction versus time for each concentration of FA which studied over the concentration range of $1-20 \mu \mathrm{g} \mathrm{mL}^{-1}$ was calculated. Graphs of log absorbance versus time for FA concentration in the range of $10-20 \mu \mathrm{g} \mathrm{mL}^{-1}\left(2.27 \times 10^{-5}-4.53 \times 10^{-5} \mathrm{M}\right)$ were plotted and all appeared to be rectilinear. Pseudo order rate constant $\left(\mathrm{k}^{\prime}\right)$ corresponding to different FA concentrations were calculated from the slopes multiplied by -2.303 . Regression of $C$ versus $\mathrm{k}^{\prime}$ gave the following equation:

$$
\mathrm{k}^{\prime}=-4.4807 C-0.0002897 \quad(\mathrm{r}=0.9510)
$$

\subsubsection{Fixed absorbance method}

Reaction rate data were recorded for different FA concentrations in the range 5-20 $\mu \mathrm{gL}^{-1}$ $\left(1.13 \times 10^{-5}-4.53 \times 10^{-5} \mathrm{M}\right)$. A preselected value of the absorbance 0.2 was fixed and the time was measured in the seconds. The reciprocal of time $(1 / \mathrm{t})$ versus the initial concentration of FA was plotted (Figure 6) and the following equation of calibration graph was obtained.

$$
1 / \mathrm{t}=0.00024551+117.5793 C \quad(\mathrm{r}=0.9918)
$$

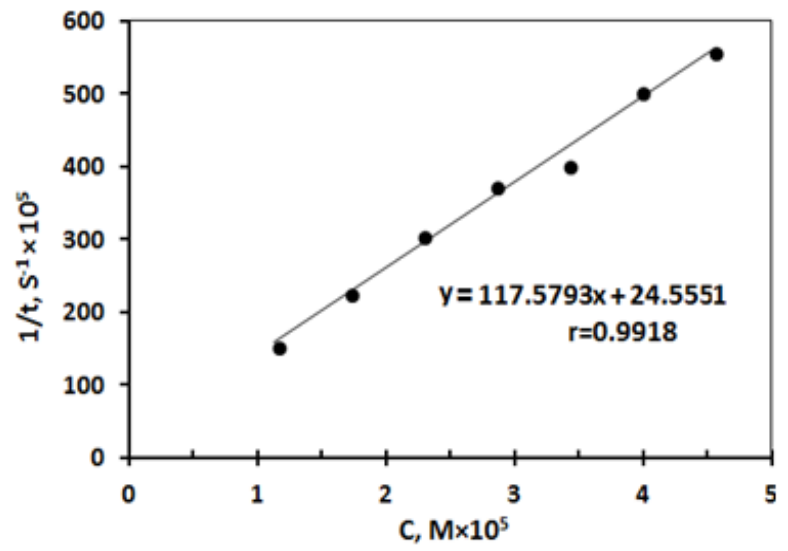

Figure 6. Calibration plot of FA for fixed absorbance method. 


\subsubsection{Fixed time method}

At preselected fixed time, the absorbance of blue colored solution containing varying amounts of FA was measured at $25^{\circ} \mathrm{C}$ and $725 \mathrm{~nm}$. Calibration graphs were constructed by plotting the absorbance against the initial concentration of FA at fixed time $0-25 \mathrm{~min}$. The regression equations, correlation coefficients and linear ranges are given in Table 1. It is clear that, the slope increases with time and the most acceptable value of $r$ was obtained for a fixed time of $15 \mathrm{~min}$. Therefore, the fixed time of 15 min was utilized for the assay of FA concentration.

Table 1. Regression equations for FA at fixed time and $25^{\circ} \mathrm{C}$.

\begin{tabular}{cccc}
\hline Time $(\mathrm{min})$ & Regression equation & Correlation coefficient & Linear range $\left(\mu \mathrm{g} \mathrm{mL} \mathrm{m}^{-1}\right)$ \\
\hline 0 & $A=0.0024 C+0.0108$ & 0.7469 & $2.5-20.0$ \\
5 & $A=0.0174 C+0.0104$ & 0.9974 & $1.5-20.0$ \\
10 & $A=0.0361 C+0.0144$ & 0.9971 & $1.0-20.0$ \\
15 & $A=0.0457 C+0.0206$ & 0.9993 & $1.0-20.0$ \\
20 & $A=0.0514 C+0.0195$ & 0.9992 & $1.0-20.0$ \\
25 & $A=0.0555 C+0.0206$ & 0.9990 & $1.0-20.0$ \\
\hline
\end{tabular}

$A$ : absorbance; $C$ : concentration.

As a result, the most acceptable values of the correlation coefficient and linear range were obtained for the rate Data $\left(\mathrm{t}_{1}=5 ; \mathrm{t}_{2}=20 \mathrm{~min}\right)$ and fixed time $(15 \mathrm{~min})$ methods. Thus, they were used for the determination of FA in pure form and pharmaceutical formulations.

\subsection{Analytical method validation}

\subsubsection{Calibration graph}

After optimizing the reaction conditions, The linearity range was found to be $1-20 \mu \mathrm{g} \mathrm{mL}$ for each method. The correlation coefficient for rate data and fixed time methods were 0.9978 and 0.9993, respectively. A linear relationship was found between the absorbance at $\lambda_{\max } 725 \mathrm{~nm}$ and the concentration of the FA in the mentioned range. The Analysis of data gave the regression equation shown in Table 2. Regression analysis of the Beer's law plots reveals a good correlation. The graph shows negligible intercept and is described by the regression equation, $A=m C+b$ (where $A$ is the absorbance of $1 \mathrm{~cm}$ layer, $m$ is the slope, $b$ is the intercept and $C$ is the concentration of the measured solution in $\mu \mathrm{g} \mathrm{mL}^{-1}$.

For fixed time method, Sandell's sensitivity coefficient of FA was found to be $0.04 \mu \mathrm{g} \mathrm{cm}^{-2}$ per 0.002 absorbance unit. The high molar absorptivity of the colored product indicates the high sensitivity. For more accurate analysis, Ringbom optimum concentration range was calculated [22]. Values of some analytical characteristics for the rate data $\left(t_{1}=5 ; t_{2}=20 \mathrm{~min}\right)$, and fixed time (15 min) methods are shown in Table 2.

Table 2. Analytical characteristics of the rate data and fixed time methods.

\begin{tabular}{l|c|c}
\hline Parameters & $\begin{array}{c}\text { Rate data } \\
\left(\mathrm{t}_{1}=5 ; \mathrm{t}_{2}=20 \mathrm{~min}\right)\end{array}$ & $\begin{array}{c}\text { Fixed time } \\
(15 \mathrm{~min})\end{array}$ \\
\hline$\lambda_{\text {max }}(\mathrm{nm})$ & 725 & 725 \\
\hline Linear concentration range $\left(\mu \mathrm{g} \mathrm{mL}^{-1}\right)$ & $1-20$ & $1-20$ \\
Ringbom optimum concentration range $\left(\mu \mathrm{g} \mathrm{mL}^{-1}\right)$ & - & $5-20$ \\
Detection limit $\left(\mu \mathrm{g} \mathrm{m}^{-1}\right)$ & 0.91 & 0.09 \\
Quantification limit $\left(\mu \mathrm{g} \mathrm{m}^{-1}\right)$ & 1.0 & 1.0 \\
Molar absorptivity $\left(\mathrm{L} \mathrm{mol}^{-1} \mathrm{~cm}^{-1}\right)$ & - & $2.32 \times 10^{4}$ \\
Stoichiometric relationship, $\mathrm{FA}: \mathrm{Fe}(\mathrm{III})$ & - & $1: 1$ \\
Sandell's sensitivity ( $\mu \mathrm{g} \mathrm{cm}^{-2}$ per 0.002 & - & 0.04 \\
absorbance unit) & $\log v=\log \Delta \mathrm{A} / \Delta \mathrm{t}=\mathrm{n} \log C$ & $A=0.0457 C+0.0206$ \\
Regression equation $^{\mathrm{a}}$ & $+\log \mathrm{k}^{\prime}$ &
\end{tabular}


Correlation coefficient, $\mathrm{r}$

\begin{tabular}{c|c}
$\log v=0.9439$ & $m=0.0457$ \\
$\log C_{\mathrm{FA}}+0.9971$ & \\
$\mathrm{k}^{\prime}=9.49 \mathrm{~s}^{-1}$ & $b=0.0206$ \\
0.9978 & 0.9993
\end{tabular}

$A=m C+b$, where A is the absorbance and $C$ is the concentration in $\mu \mathrm{g} \mathrm{mL}^{-1}$. $\log \frac{\Delta \mathrm{A}}{\Delta \mathrm{t}}=\log \mathrm{k}^{\prime}+n \log C$, where $\frac{\Delta \mathrm{A}}{\Delta \mathrm{t}}$ reaction rate, $\mathrm{k}^{\prime}$ is the pseudo order rate constant, $\mathrm{c}$ is the concentration of the FA $(\mathrm{mol} / \mathrm{L})$ and $\mathrm{n}$ is the order of the reaction.

\subsubsection{LOD and LOQ}

The minimum level at which the investigated compound can be reliably detected (limit of detection, LOD) and quantified (limit of quantitation, LOQ) was determined experimentally for fixed time $(15 \mathrm{~min})$ and rate data $\left(\mathrm{t}_{1}=5 ; \mathrm{t}_{2}=20 \mathrm{~min}\right)$ methods. LOD for fixed time method was calculated by statistical treatment of calibration data $(n=10)$ by considering ten calibration points using the following equation [23]:

LOD $=\sqrt{S_{\circ}^{2} \frac{n-2 t}{n-1 b}}$

where $n$ is the number of standard samples $(n=10), t$ is the value of student's $t$ for four degrees of freedom at $95 \%$ confidence level and equal to $2.776, b$ is the slope of the regression line and $S_{o}$ is the variance and was calculated using the equation [24]:

$S_{o}^{2}=\sum\left(A_{\text {exp }}-A_{\text {calc }}\right)^{2} / n-2$

LOD for rate data method was calculated by statistical treatment of calibration data $(n=9)$ by considering nine calibration points using the following equation [25]:

LOD $=\frac{t}{b} \sqrt{S_{o}^{2} n \frac{n-2}{n-1}}$

where $n$ is the number of standard samples $(n=9), t$ is the value of student's $t$ for four degrees of freedom at $95 \%$ confidence level and equal to $2.776, b$ is the slope of the regression line and $S_{o}$ is the variance and was calculated using the equation [26]:

$$
\mathrm{S}_{\circ}^{2}=\sqrt{\frac{\left(\log \frac{\Delta A}{\Delta t} \exp -\log \frac{\Delta A}{\Delta t} \operatorname{calc}\right)^{2}}{n-2}}
$$

The LOD of FA was found to be 0.09 and $0.91 \mu \mathrm{g} \mathrm{mL}^{-1}$ for fixed time and rate data methods, respectively. The LOQ of FA was considered to be the lowest concentration in the calibration curves, as shown in table 2.

\subsubsection{Stoichiometry of the reaction}

The stoichiometry of the reaction was studied adopting the limiting logarithmic method [27]. The ratio of the reaction between FA and Fe(III) was calculated by dividing the slope of Fe(III) curve over the slope of the FA curve (Figures 7(a) and 7(b)). It was found that the ratio was 1:1 (Fe(III) to FA). 


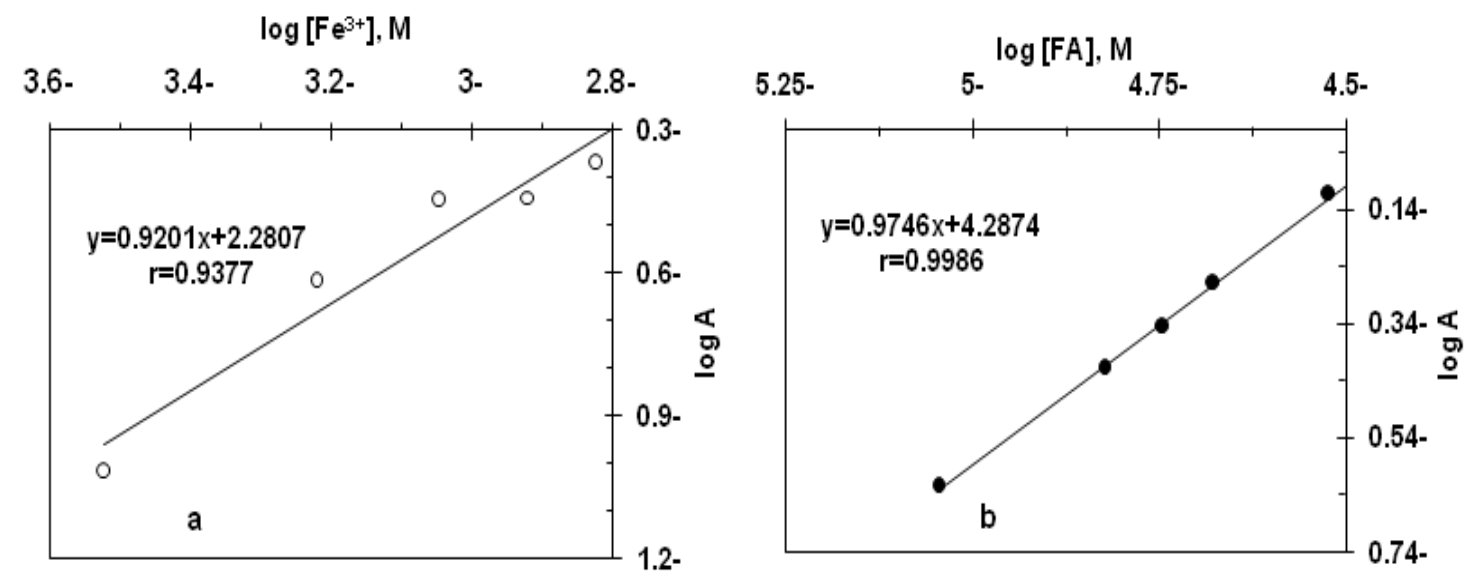

Figure 7. Stoichiometry of the reaction between $\mathrm{FA}$ and $\mathrm{Fe}^{3+}$ adopting limiting logarithmic method. (a) $\mathrm{C}_{\mathrm{FA}}=15.0 \times 10^{-6} \mathrm{M}, \mathrm{C}_{\mathrm{Fe}}^{3+}=\left(3.0 \times 10^{-4}-15.0 \times 10^{-4} \mathrm{M}\right), \mathrm{C}_{\mathrm{K} 3[\mathrm{Fe}(\mathrm{CN}) 6]}=2.5 \times 10^{-4} \mathrm{M}$. (b) $\mathrm{C}_{\mathrm{Fe}}{ }^{3+}=15.0 \times 10^{-4}$ $\mathrm{M}, \mathrm{C}_{\mathrm{FA}}=\left(0.9 \times 10^{-5}-3.0 \times 10^{-5} \mathrm{M}\right), \mathrm{C}_{\mathrm{K} 3[\mathrm{Fe}(\mathrm{CN}) 6]}=2.5 \times 10^{-4} \mathrm{M}$.

\subsubsection{Accuracy and precision}

The accuracy and precision of the proposed methods were carried out by five determinations at three different concentrations. Percentage relative standard deviation (RSD \%) as precision and percentage recovery as accuracy of the suggested methods were calculated and showed in Table 3 . The values of relative standard deviations for different concentrations of FA determined from the calibration curves. These results of accuracy and precision show that the proposed methods have good repeatability and reproducibility. The proposed methods were found to be selective for the estimation of FA in the presence of various tablet excipients. For this purpose, a powder blend using typical tablet excipients was prepared along with the vitamin and then analyzed. The recoveries were not affected by the excipients and the excipients blend did not show any absorption in the range of analysis.

Table 3. Accuracy and precision for the determination of FA in bulk powder by the proposed rate data and fixed time methods.

\begin{tabular}{|c|c|c|c|c|c|c|}
\hline \multirow{2}{*}{ Method } & \multicolumn{3}{|c|}{$\mathrm{FA}, \mu \mathrm{g} \mathrm{mL} L^{-1} *$} & \multirow{2}{*}{ RSD \% } & \multirow{2}{*}{ Confidence limit } & \multirow{2}{*}{ Recovery \% } \\
\hline & Taken & Found $^{\mathrm{a}}$ & SD & & & \\
\hline \multirow{3}{*}{ Rate data } & 5.00 & 4.97 & 0.13 & 2.62 & $4.97 \pm 0.16$ & 99.40 \\
\hline & 10.00 & 10.06 & 0.22 & 2.19 & $10.60 \pm 0.27$ & 100.60 \\
\hline & 15.00 & 14.97 & 0.24 & 1.60 & $14.97 \pm 0.29$ & 99.80 \\
\hline \multirow{3}{*}{ Fixed time } & 5.00 & 4.96 & 0.13 & 2.62 & $4.96 \pm 0.17$ & 99.20 \\
\hline & 10.00 & 9.95 & 0.25 & 2.51 & $9.95 \pm 0.31$ & 99.50 \\
\hline & 15.00 & 14.95 & 0.37 & 2.47 & $14.95 \pm 0.39$ & 99.67 \\
\hline
\end{tabular}

${ }^{\mathrm{a}}$ Five independent analyses.

\subsection{Application to the pharmaceutical dosage forms}

The proposed methods were applied to the tablets. The ingredients in the tablets did not interfere in the experiments. The applicability of the proposed methods for the assay of FA in formulations was examined by analyzing various formulations and the results are tabulated in Table 4 were compared to the official for FA [1] by means of $t$ - and $F$-values at $95 \%$ confidence level. In all cases, the average results obtained by proposed methods and official method were statistically identical, as the difference between the average values had no significance at $95 \%$ confidence level. The low values of RSD\% show the results are reproducible. The proposed methods are simple, 
sensitive and reproducible and can be used for routine analysis of FA in pure form and in pharmaceutical formulations.

Table 4. Determination of FA in different pharmaceutical formulations by the proposed and official methods.

\begin{tabular}{|c|c|c|c|c|}
\hline \multirow{3}{*}{ Formulation } & \multirow{3}{*}{ Label claim } & \multicolumn{3}{|l|}{$\%$ Found $^{\mathrm{a}} \pm \mathrm{SD}$} \\
\hline & & \multicolumn{2}{|c|}{ Proposed methods } & \multirow{2}{*}{ Official method [1] } \\
\hline & & Rate data & Fixed time & \\
\hline \multirow{3}{*}{ Folmed $^{\mathrm{b}}$} & \multirow{3}{*}{$5 \mathrm{mg} / \mathrm{tab}$} & $100.05 \pm 0.33$ & $99.07 \pm 0.16$ & $99.85 \pm 0.28$ \\
\hline & & $t=0.05$ & $t=2.01$ & $t=0.73$ \\
\hline & & $F=1.39$ & $F=3.06$ & \\
\hline \multirow{3}{*}{ Kanafolic $^{c}$} & \multirow{3}{*}{$5 \mathrm{mg} / \mathrm{tab}$} & $102.52 \pm 0.43$ & $100.40 \pm 0.36$ & $98.15 \pm 0.35$ \\
\hline & & $t=1.95$ & $t=0.38$ & $t=2.12$ \\
\hline & & $F=1.51$ & $F=1.06$ & \\
\hline
\end{tabular}

${ }^{\mathrm{a}}$ Five independent analyses. At $95 \%$ confidence level t-value is 2.776 and F-value is $6.26 .{ }^{\mathrm{b}}$ Supplied by medico labs, Syria, ${ }^{c}$ Supplied by kanawati products, Syria.

\section{CONCLUSION}

The proposed procedures were applied to determine FA in its pharmaceutical formulations. The results indicate the high accuracy and precision. The proposed method has the advantages of being virtually free from interferences by excipients or from common degradation products. The results obtained were compared statistically by the student's t-test (for accuracy) and the variance ratio F-test (for precision) with those obtained by the reference method on samples of the same batch. The values of t- test and F-tests obtained at 95\% confidence level and four degrees of freedom did not exceed the theoretical tabulated value indicating no significant difference between the methods compared.

\section{Acknowledgement}

The authors express their thanks to Dr Ayman Karam, Department of Chemistry, AL Baath University, Faculty of Sciences, for providing all the assistance during the work.

\section{References}

[1] British Pharmacopoeia, Her Majesty Stationery Officer, London, UK. (2007).

[2] Mangas A, Coveǹas, R Geffard, K Geffard, M Marcos, P Insausti, R Dabadie, M.P., Neurosci Lett. 362 (2004) 258.

[3] Kanjilal G, Mahajan S.N, Ramana R.G., Analyst. 100 (1975) 19.

[4] Padmarajaiah N, Ramanathapura A.V, Hemmige S.Y., Anal Bio chem. 307 (2002) 316.

[5] Zhang B.T, Zhao L, Lin J.M., Talanta. 74 (2008) 1154.

[6] Nie F, He Y, Lu J., Micro chem J. 65 (2000) 319.

[7] Zhang Z.Q, Tang Y., Anal Bio chem. 381(2005) 932.

[8] Al-warthan A.A., Anal Sci. 10 (1994) 919.

[9] Manzoori J.L, Jouyban A, Amjadi M, Soleymani,J., Luminescence. 26 (2011) 106.

[10] Zhao S, Yuan H, Xie C, Dan X. D., J Chromatogr A. 1107 (2006) 290.

[11] Wei S, Zhao F, Xu Z, Zeng B., Microchim Acta. 152 (2006) 285. 
[12] Mirmoghtadaie L.A, Ensafi A, Kadivar M, Norouzi P., Sci Eng. C 33 (2013) 1753.

[13] Höller U, Brodhag C, Knöbel A, Peter Hofmann P, Spitzer V., J Pharm Biomed Anal. 31 (2003) 151.

[14] Amidžić R, Brboric J, Čudina O, Vladimirov S., J Serb Chem Soc. 70 (2005) 1229.

[15] Radhika K, Srinath N, Sumanth K.S, Neelima S, Krishna V.P., KIJAP 3 (2012) 701.

[16] Nelson B.C.E, Sharpless K.E, Sander L.C. y., J Chromatogr A. 1135 (2006) 203.

[17] Shishehbore M.R, Sheibani A, Haghdost A., Spectrochim Acta Part A. 81(2011) 304.

[18] Ashour S, Khateeb M., Arabian J Chem. 4 (2011) 299.

[19] Ashour S, Bahbouh M, Khateeb M., Int J Biomed Sci. 6 (2010) 19.

[20] Kopanica M, Satra V, Echschlager K, Rorsak I, Koduys Z, Sandr K, Eds., Elsevier, Amsterdam, The Netherlands, (1983).

[21] Persez-Bendit, D., Silva, M., chapter 11, John Wiley \& Sons, New York, NY, USA. 1988.

[22] Ringbom A, Zeitschrift für Analytische Chemie. 115 (1939) 332.

[23] Morelli B., Analyst (London). 108 (1983) 870.

[24] Nalimov V.V., Pergamon Press, Oxford. (1963) 189.

[25] Morelli B., J Pharm Biomed Anal. 5 (1987) 577.

[26] Morelli B., Analyst. 113 (1988) 1077.

[27] Rose J., Advanced Physico-Chemical Experiments, Pittman, London, UK. (1964). 